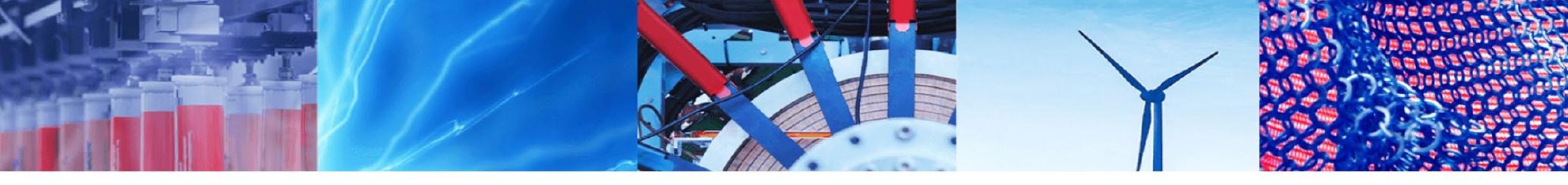

Research Article

\title{
Electrical properties of gadolinia-doped ceria for electrodes for magnetohydrodynamic energy systems
}

\author{
Michael S. Bowen ${ }^{1,2}$ (1) Michael Johnson ${ }^{1,2} \cdot$ Ryan McQuade $^{2} \cdot$ Bryce Wright $^{1,2} \cdot$ Kyei-Sing Kwong ${ }^{1} \cdot$ Peter Y. Hsieh ${ }^{1}$. \\ David P. Cann ${ }^{1,2} \cdot$ C. Rigel Woodside ${ }^{1}$
}

Received: 5 April 2020 / Accepted: 28 July 2020 / Published online: 19 August 2020

(c) This is a U.S. Government work and not under copyright protection in the U.S.; foreign copyright protection may apply 2020

\begin{abstract}
High temperature conducting ceramics are of current interest for use as electrode materials for magnetohydrodynamic (MHD) power generation systems for their high conductivity values and their excellent stability under extreme conditions including operating temperatures above $2000^{\circ} \mathrm{C}$. Ceria doped with Gd (GDC) has been extensively studied for intermediate temperature applications and shows promise as an efficient electrode material. A summary of the current understanding of the electrical properties of GDC is provided with an emphasis on the higher temperature limits. Experiments to further validate the conclusions drawn in the literature review confirm that with electrical conductivities near $10 \mathrm{~S} / \mathrm{m}$ at $1100^{\circ} \mathrm{C}$ make GDC a good candidate electrode material for an MHD power generator.
\end{abstract}

Keywords Magnetohydrodynamics · Energy materials · Doped ceria · Energy conversion · Electroceramics

\section{Introduction}

Research and development of a direct power extraction concept using magnetohydrodynamics (MHD) is motivated by the fact that this technology can provide a significant increase in energy efficiency for chemical-toelectrical energy conversion by enabling the operation of power plants at higher temperatures [1]. By utilizing high temperature gases as a working fluid in a MHD topping unit, a combined-cycle coal-fired power plant could eventually lead to plant thermal efficiencies above $60 \%$ [2]. While the thermodynamic advantages of a MHD system have been known for years, legacy US Department of Energy (DOE) research was impeded by challenges in the supporting technology and unfavorable techno-economics. Fortunately, technological advancements in magnets, materials, and thermal fluids have improved since previous DOE research efforts, improving the viability of MHD power generation. More recently, interest in using oxy-fuel combustion to enable carbon dioxide capture has renewed R\&D into MHD topping cycles especially with the increased use of high temperature oxy-fuel combustion [3]. Thus, implementation of MHD technology has the potential to significantly reduce fossil fuel consumption and reduce greenhouse gas emissions.

A great challenge in development of a functional generator is material selection. The working fluid of a MHD generator creates an extreme environment with combustion temperatures as high as $3000^{\circ} \mathrm{C}$, gas velocities up to mach-2, and the presence of ionizable species, specifically potassium vapor. Materials are functionally exposed to less intense conditions at the boundary layer, with temperatures up to $2400^{\circ} \mathrm{C}[3,4]$. Previous versions of MHD generators used cold electrodes which were

Electronic supplementary material The online version of this article (https://doi.org/10.1007/s42452-020-03280-2) contains supplementary material, which is available to authorized users.

Michael S. Bowen, mstevenbowen@gmail.com | 'US Department of Energy, National Energy Technology Laboratory, 1450 SW Queen Ave, Albany, OR 97321, USA. ${ }^{2}$ Materials Science, Oregon State University, Corvallis, OR 97331, USA. 
high electrical conductivity metals; such as tungsten or copper, with extreme water cooling to avoid reaching melting temperatures $[1,5]$. With direct exposure to the seeded plasma, oxidation and potassium corrosion resulted in material failure. Alternative designs for use with coal combustion relied on a protective slag which would shield the electrodes from potassium and insulate the plasma to increase temperatures and improve efficiencies. The failure in this design was potassium diffusion through the slag, at which point the temperature at the surface of the electrodes was below the dewpoint of potassium resulting in a conductive liquid which shorted the electrode pairs [5-7]. A review of MHD technologies conducted in 2004 reports a more in-depth analysis of designs of MHD technologies [5].

This motivates a transition to hot electrodes with direct exposure to the plasma, which limits materials to refractory metals and high temperature ceramics [1]. There are a number of oxides which can perform as conductors at MHD operating conditions, but the two of greatest interest during initial MHD work were zirconia-based and lanthanum chromate-based oxides [6-15]. Zirconia is stable in a monoclinic phase, which is generally a poor conductor, but rare earths and group IV fluorites stabilize the system in the cubic fluorite phase, which shows to be a good electrical conductor [16]. Yttria stabilized zirconia (YSZ) and ceria-zirconia were both tested in early research; but failure occurred likely due to potassium corrosion, specifically reaction with zirconium oxide $[6,8,14]$. This drives a push for zirconia free, high temperature conducting oxides. One particular system, Gd doped ceria (GDC), is used in place of and in conjunction with YSZ, indicating they share many similar properties in operating temperature ranges, corrosion resistance, and electrical properties [17-21].

In order to be considered a viable candidate material for MHD power generation, there are a number of stability conditions and material properties that must be met. Phase stability plays a huge role, as materials ideally can withstand operating temperatures ranging from 1500 to $2100^{\circ} \mathrm{C}$ depending on thermal conductivity. Furthermore, materials must resist chemical reactions with potassium, specifically $\mathrm{K}$ vapor which is highly reactive. For optimal power generation, the conductivity of the material should be at least on the same order of magnitude as the plasma conductivity, which is theorized to be between $10^{1}$ to $10^{2} \mathrm{~S} / \mathrm{m}[3,4]$. Finally, a specific consideration for oxide materials is the $\mathrm{pO}_{2}$ level to determine whether the environment is reducing or oxidizing. This can vary vastly based on the application, the equivalence ratio (a measure of fuel-oxygen), seed concentration and temperature of the gases. For oxy-methane combustion, oxygen partial pressures range between $10^{-9}$ and $1 \mathrm{~atm}$. This work is solely focused on the electrical properties, though other work is being carried out to address other requirements for the material system.

\section{Review}

This work considers use of cerium oxide doped with gadolinium, $\mathrm{Gd}_{x} C e_{1-x} \mathrm{O}_{2-\frac{x}{2}}(\mathrm{GDC})$ as a high temperature electrode material for MHD applications. The GDC system has broad interest for oxygen transport applications including solid oxide fuel cells (SOFC) and catalysis [17-21], which are heavily reliant on maximizing oxygen transport. As a result, extensive research has been carried out on the electrical properties of doped ceria, particularly GDC. This work has accumulated the results of many others in order to draw general conclusions about properties of GDC and further conduct an independent investigation to ensure our techniques meet the standards of current state of the art.

Ceria is stable in the cubic fluorite structure $(\mathrm{Fm}-3 \mathrm{~m})$ with no reported phase changes up to the melting point around $2750 \mathrm{~K}$ [22]. Gadolinium oxide $\left(\mathrm{Gd}_{2} \mathrm{O}_{3}\right)$ is typically stabilized in a monoclinic phase, but transitions to the cubic c-type rare earth structure with small amounts of Ce doping. The similarity in structure between the two supports the stable solid solution between $\mathrm{CeO}_{2}$ and $\mathrm{Gd}_{2} \mathrm{O}_{3}$. A phase diagram simulation from Žguns [23] shows a stable fluorite phase for Gd doped ceria (GDC) with intermediate amounts of doping and a phase transition to c-type rare earth near $50 \%$.

Undoped ceria has relatively low electrical conductivity at atmospheric oxygen levels. Blumenthal et al. [24] show that under reducing conditions, however, the conductivity exhibits a $\mathrm{pO}_{2}^{-1 / 5}$ dependence and Panlener [25] found the same relation for oxygen vacancies in reduced $\mathrm{CeO}_{2}$. The promotion of oxygen vacancies derives from multiple valence states of cerium, represented by the defect reaction below in Eq. (1). There is a similar reaction of hole compensation which explains the electronic conductivity of ceria in Eq. (2). The $\mathrm{pO}_{2}$ dependence is consistent with p-type conductivity according to defect equilibrium analysis by Smyth [26]. The introduction of $\mathrm{Gd}^{3+}$ doping improves conductivity by the defect reaction in Eq. (3). This reaction shows the promotion of oxygen vacancies with $\mathrm{Gd}$ doping, but there is a similar electronic compensation to Eq. (2), which is likely to occur in oxidizing environments (Fig. 1).

$$
\begin{aligned}
& 2 \mathrm{CeO}_{2} \stackrel{\mathrm{CeO}_{2}}{\longrightarrow} 2 \mathrm{Ce}_{\mathrm{Ce}}^{\prime}+3 \mathrm{O}_{\mathrm{O}}^{x}+\mathrm{V}_{\mathrm{O}}^{\prime \prime}+\frac{1}{2} \mathrm{O}_{2} \uparrow \\
& \mathrm{CeO}_{2} \stackrel{\mathrm{CeO}_{2}}{\longrightarrow} \mathrm{Ce}_{\mathrm{Ce}}^{\prime}+2 \mathrm{O}_{\mathrm{O}}^{x}+h \\
& \mathrm{Gd}_{2} \mathrm{O}_{3} \stackrel{\mathrm{CeO}_{2}}{\longrightarrow} 2 \mathrm{Gd}_{\mathrm{Ce}}^{\prime}+3 \mathrm{O}_{\mathrm{O}}^{x}+\mathrm{V}_{\mathrm{O}}^{.}
\end{aligned}
$$


Fig. 1 Schematic of a combustion driven open-cycle MHD power generator showing direct plasma exposure of the channel wall, composed of electrode and insulator segments

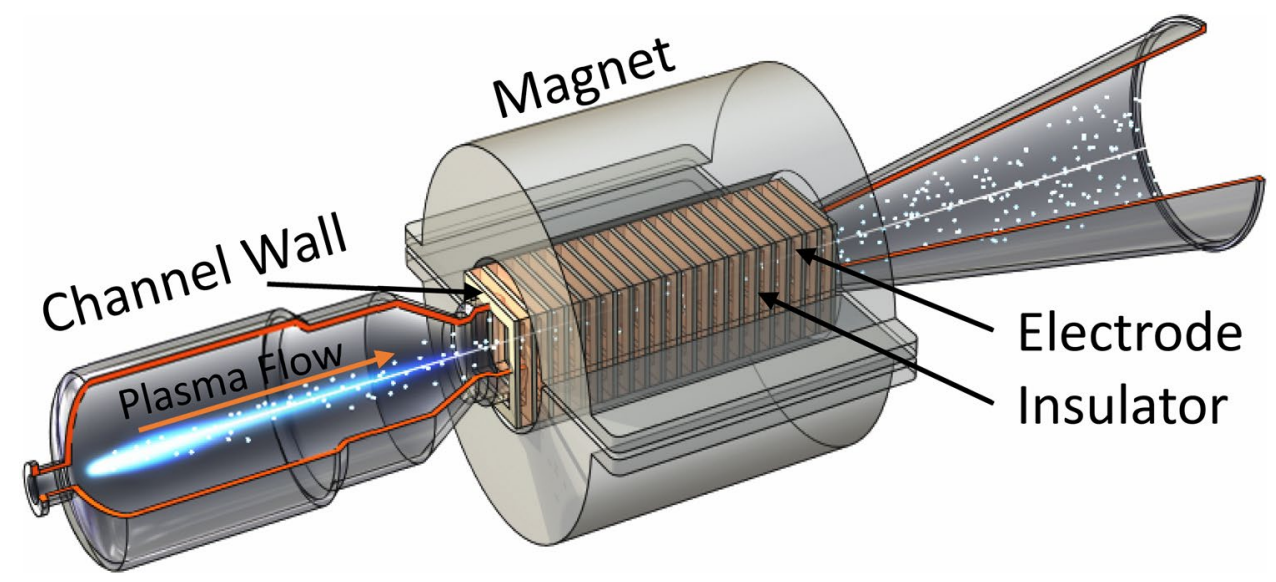

An extensive literature search into measured electrical properties of GDC has resulted in numerous sources reporting electrical conductivity for various dopant levels $[18,19,27-42]$. Most reports included data on compositions with 10\% (10GDC) and 20\% (20GDC) dopant levels as summarized in Figs. 2 and 3 respectively. The conduction mechanisms in this system are oxygen vacancies and small polarons, concluded in the review by Mogensen [22], which are both hopping mechanisms. As a result, an additional $\frac{1}{T}$ term is included in the Arrhenius equation to determine the activation energy of the system, given by [22]:

$\sigma=\frac{A}{T} \exp \left[-\frac{E_{a}}{k_{B} T}\right]$

where $E_{a}$ is the activation energy, and $A$ is the intercept conductivity in $\frac{S \cdot K}{\mathrm{~cm}}$.

The conductivity data shown in Figs. 2 and 3 show quite significant variability in the magnitude of the conductivity values. Using $500{ }^{\circ} \mathrm{C}$ as a reference point,
Fig. 2 Comparison of accumulated data from various sources [27-37] of $G d_{0.1} C e_{0.9} O_{1.95}$

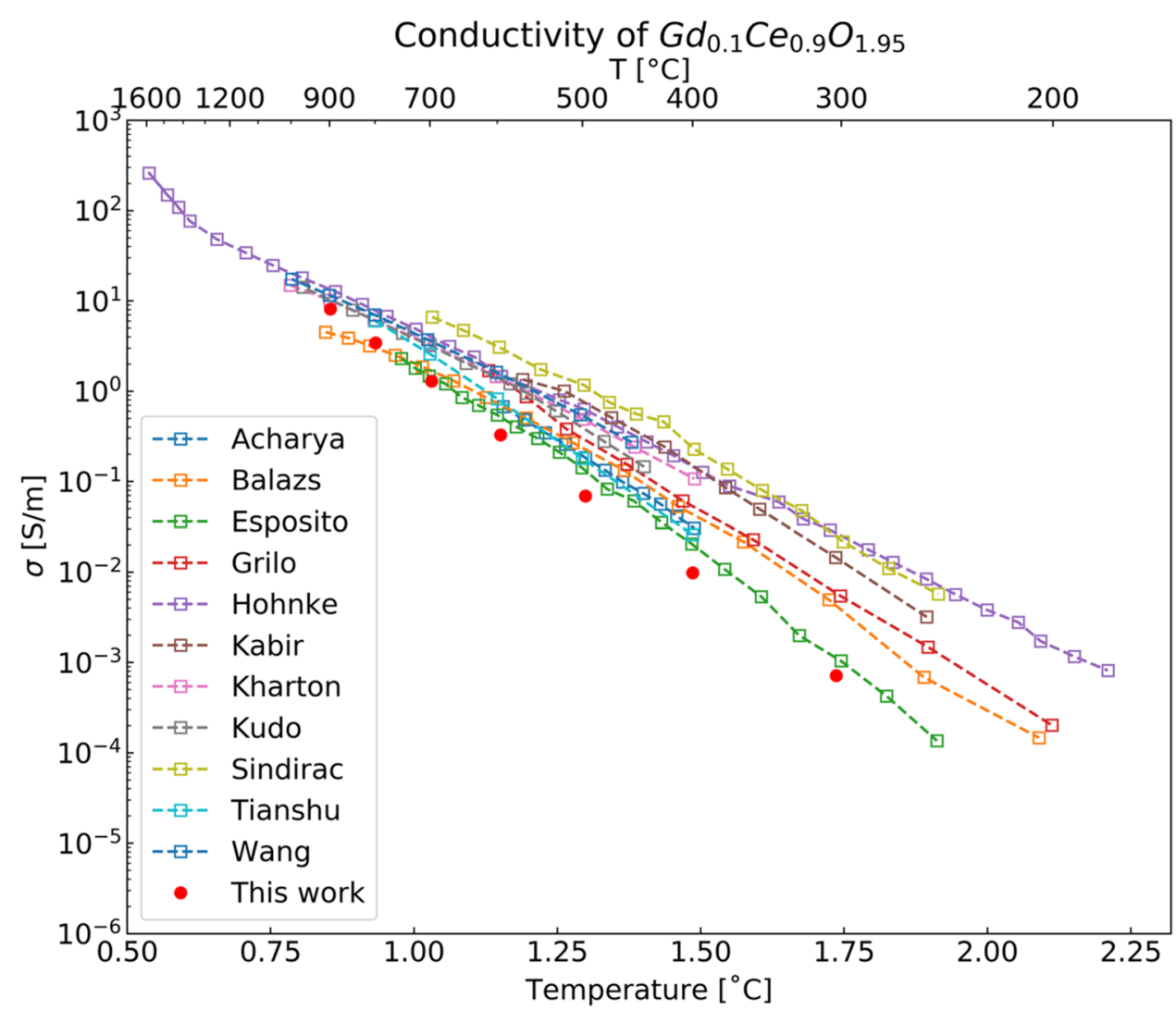

SN Applied Sciences 
Fig. 3 Comparison of accumulated data from various sources $[18,19,27,29,31,33,36$, 38-42] of $\mathrm{Gd}_{0.2} \mathrm{Ce}_{0.8} \mathrm{O}_{1.9}$

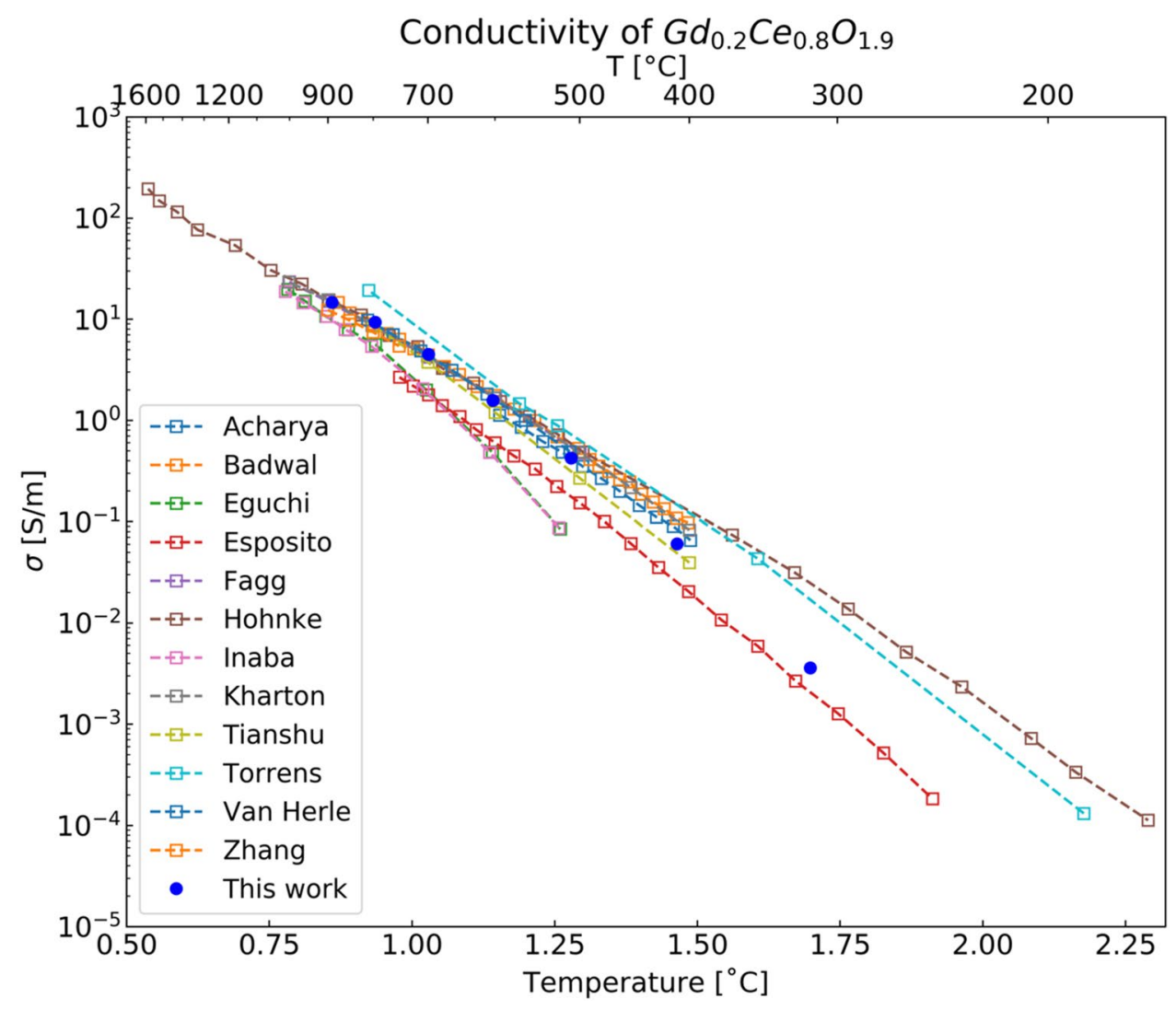

20 mol\% Gd-doped $\mathrm{CeO} 2$ exhibited an average conductivity of $0.38 \mathrm{~S} / \mathrm{m}$ with a standard deviation of 0.19 $\mathrm{S} / \mathrm{m}$, and $10 \mathrm{~mol} \% \mathrm{Gd}$-doped $\mathrm{CeO} 2$ exhibited a larger variation with an average conductivity of $0.43 \mathrm{~S} / \mathrm{m}$ with a standard deviation of $0.26 \mathrm{~S} / \mathrm{cm}$. There are many potential explanations for these large ranges of conductivity values. The data represented in Figs. 2 and 3 were obtained from different measurement techniques, including ac impedance spectroscopy vs dc I-V measurements and four-point vs two-point probe methods, as well as different electrodes which may impart differences in the contact resistance. In addition, while the compositions are nominally the same stoichiometry, the purity of the starting materials varied between the different literature reports. This is likely to affect the overall conductivity values, especially when considering the grain boundary contribution to the overall conductivity. There may also be differences in oxygen stoichiometry due to the presence of impurities or variations in processing conditions. Finally, in considering that all the samples in Figs. 2 and 3 were polycrystalline ceramics, variations in density and grain size would be expected to influence variability in the measured conductivity values.

\section{Methods}

Ceramic pellets were fabricated for this study to confirm the current state of the art in electrical conductivity of GDC. Starting $\mathrm{CeO}_{2}(99.9 \%,<5 \mu \mathrm{m}$, Sigma Aldrich) and $\mathrm{Gd}_{2} \mathrm{O}_{3}$ (99\%, Sigma Aldrich) powders were mixed in the appropriate stoichiometric ratios as reported in Online Resource 1. The mixed powders were combined with ethanol and $8 \%$ YTZ media, then milled for $8 \mathrm{~h}$. Initial powders were reported by Sigma Aldrich to have a D50 distribution $<5 \mu \mathrm{m}$ further confirmed by measurements with a laser diffraction particle size analyzer (Malvern Mastersizer 3000). Post-milled powders were measured to be $<2.5 \mu \mathrm{m}$ using the same measurement. The milled powders were then dried at $115^{\circ} \mathrm{C}$ for $8 \mathrm{~h}$ and pressed into green bodies using a $13 \mathrm{~mm}$ diameter die under $170 \mathrm{MPa}$ pressure for $30 \mathrm{~s}$. The green bodies were finally sintered at $1600^{\circ} \mathrm{C}$ for $30 \mathrm{~h}$ in magnesium oxide crucibles. This method differs from standard solid-state techniques in that no calcination process was used, motivated by stable fluorite phase of the ceria powder and long sintering times.

Densities of sintered pellets were measured per Archimedes principle with a Mettler Toledo XS64 balance and the standard density kit. Averages of eight samples of each composition showed above $95 \%$ densities for nearly all 
samples. Phase stability was verified by performing X-ray diffraction (XRD) with a Bruker AXS D8 Discover on pellets crushed into powders with a mortar and pestle using a Bragg-Brentano geometry. Fluorite peak locations were extracted, and a lattice constant was calculated from each peak using Bragg's law. The experimental lattice parameter was approximated as the average lattice spacing of all peaks to calculate theoretical density.

Electrical conductivity was measured on disk and bar samples using 2-point AC Electrochemical Impedance Spectroscopy (EIS), outlined by Sinclair and others [44], to extract bulk and grain boundary conductivities. Disk samples were approximately $10.75 \mathrm{~mm}$ diameter with varying heights between $1.5 \mathrm{~mm}$ and $3 \mathrm{~mm}$. Platinum electrodes were applied to the circular faces and AC EIS was performed using a Solartron SI1260A impedance analyzer along with the Solartron 1296A dielectric interface. Non-linear least squares fittings were performed with the following equivalent circuit model (Fig. 4) to extract grain (g), grain boundary (g.b.), and electrode (el.) resistances.

$Z=R_{\text {inst }}+(R Q)_{g}+(R Q)_{\text {g.b. }}+(R Q)_{e l}$.

$R Q=\frac{1}{R}+T(i \omega)^{n}$

The total sample conductivity is a combination of grain and grain boundary resistivities as follows:

$\sigma_{\text {tot }}=\frac{1}{\rho_{\text {tot }}}=\frac{1}{\rho_{g}+\rho_{g . b .}}$

where resistivity is defined by:

$\rho=\frac{R A}{L}$

Separate electrical conductivity measurements were performed with a 4-point DC method on bar sample geometries to verify the total conductivity values extracted from AC EIS. Pellets pressed into $25.4 \mathrm{~mm}$ diameter by $3.5 \mathrm{~mm}$ height were cut into bars with final geometries of approximately $3.5 \mathrm{~mm}$ length by $5 \mathrm{~mm}$ width by $18.5 \mathrm{~mm}$ height. Surface electrodes were applied to both end surfaces as well as on the perimeter of a cross section at $5 \mathrm{~mm}$ from each end. A DC current was applied at the surfaces using a Keithley 6221 Current Source Meter while measuring the voltage across the ring electrodes with a Keithley $2182 \mathrm{a}$ nanovoltmeter. Total sample resistance is calculated from the slope of the I-V curve and conductivity is calculated from Eqs. (5-8) above, with the length $L$ being the spacing between ring electrodes.

All electrical measurements were performed in a NorECS ProboSTAT high temperature measurement cell heated in a horizontal tube furnace at $100{ }^{\circ} \mathrm{C}$ increments from room temperature to $1100^{\circ} \mathrm{C}$. The temperature inside the cell was tracked with an r-type thermocouple logged with time to ensure temperature stability.

\section{Results and discussion}

X-Ray diffraction patterns are shown in Fig. $5 b$ for increasing gadolinium content. Peak locations verify the cubic fluorite structure for all compositions. As Gd content increases, peaks shifted to the left indicating an increase in lattice parameter which is expected [45]. The average lattice spacing was calculated from peak heights and reported in Online Resource 1. The respective $d$-spacing shows trends similar to those observed by Artini et al. [46], verifying the deviation from Vegard's Law despite being a solid solution. The majority of pellets fabricated were greater than $95 \%$ of theoretical density. Pure $\mathrm{CeO}_{2}$ is found to have lower densities, which indicates Gd doping improves sinterability. Samples with density below $95 \%$ were not used to measure electrical properties.

At temperature increments of $100^{\circ} \mathrm{C}, \mathrm{AC}$ EIS measurements were performed on two disk samples of each composition to resolve grain and grain boundary resistances. Figure 6a displays impedance spectra representative of the specimens in this study, where only two mechanisms are

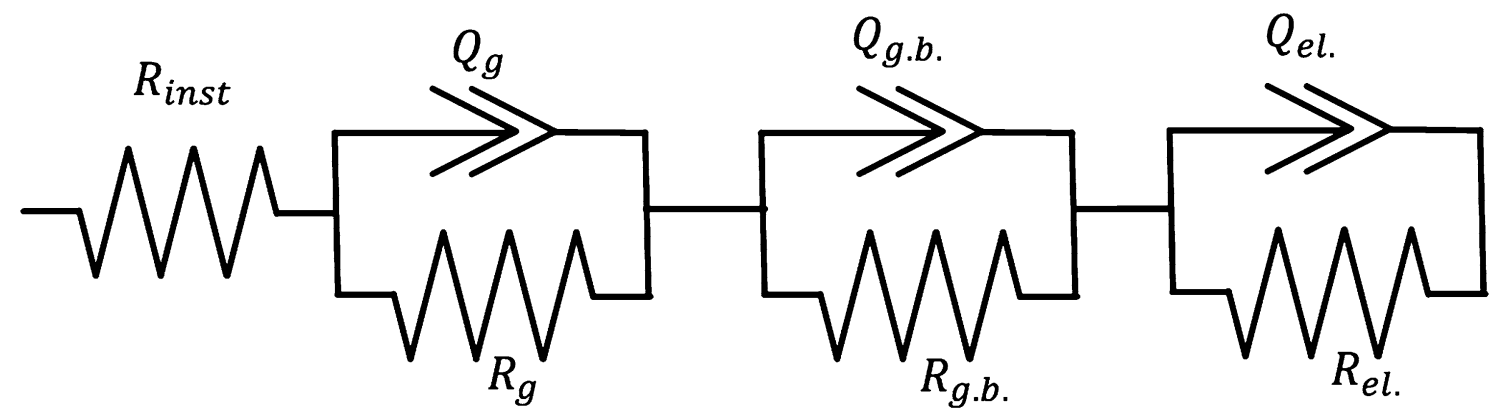

Fig. 4 Equivalent circuit diagram of a brick layer model for AC circuit modelling [44] 

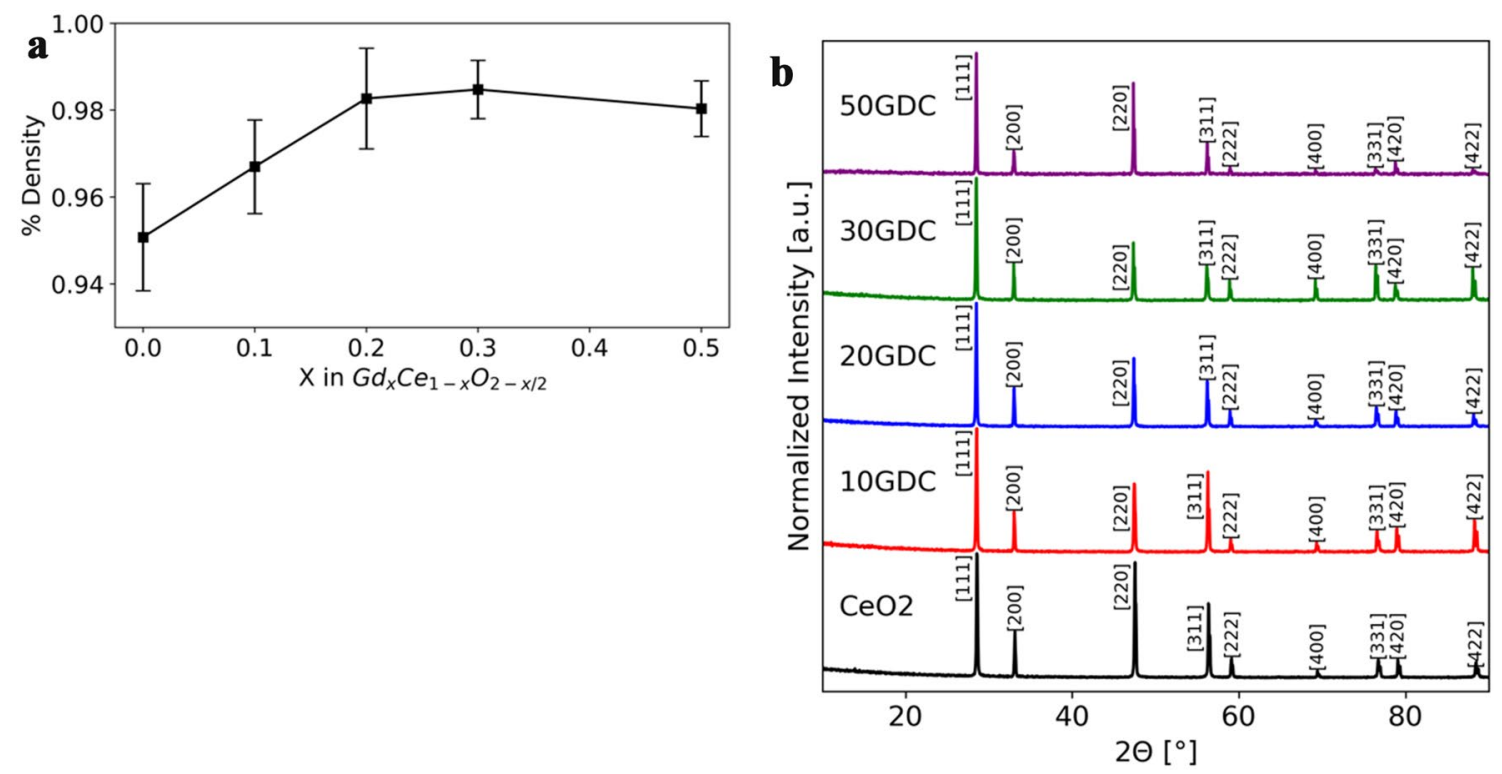

Fig. 5 a left: Average density and standard deviation of 8 samples of each GDC composition. $\mathbf{b}$ right: XRD patterns of GDC pellets ground into powders. The Miller indices shown are for fluorite reflections
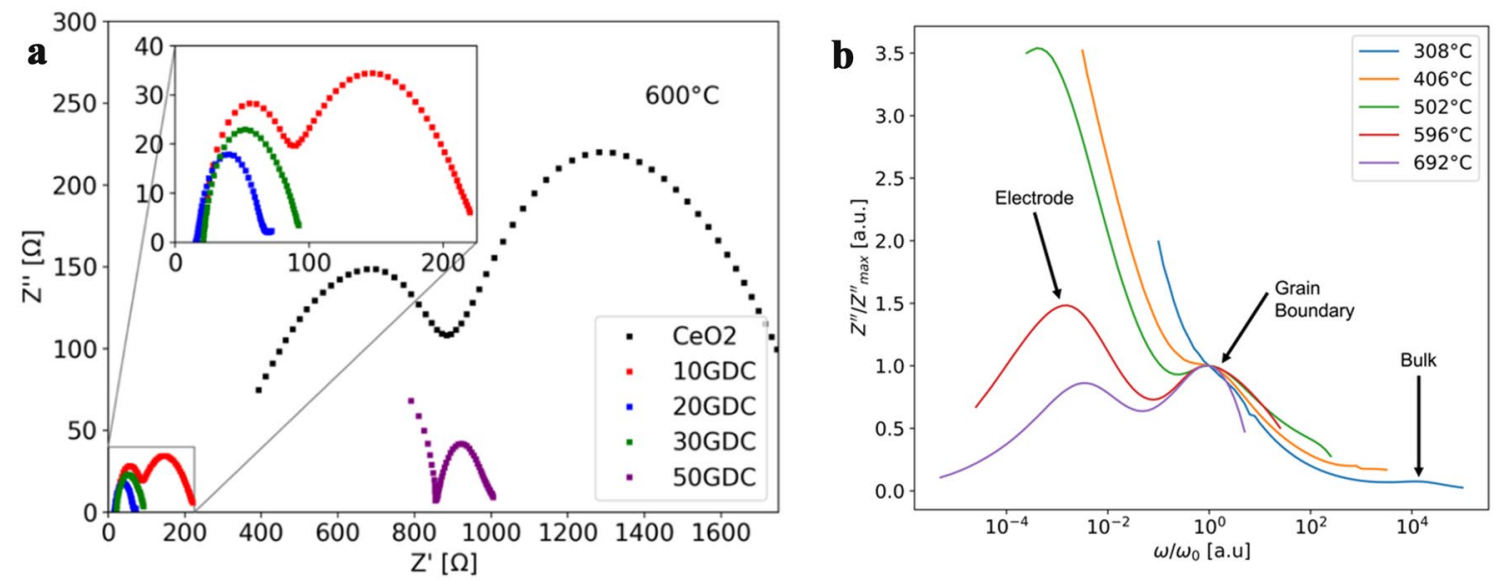

Fig. 6 a Impedance spectra of one sample of each composition at $600{ }^{\circ} \mathrm{C}$ showing the grain boundary for each except 50 GDC. Second semicircles, where present, represent electrode contributions.

b Imaginary bode plot normalized to the frequency and impedance at which the peak value of the grain boundary impedance occurs for a pure ceria disk sample

activated throughout the frequency range of the measurement for any given temperature, aside from a few samples. As a result, data is typically fitted with only two of the three RQ elements in Eq. (5) and Fig. 4 above. Whether the two elements correspond to the bulk, grain boundary, or electrode is determined based on the capacitance of the fitted equivalent circuit elements [43, 47]. Furthermore, as the temperature increased, the frequency at which the peak imaginary resistance occurs, known as $\omega_{0}$, increased following the Arrhenius equation. Figure $6 \mathrm{~b}$ depicts the gradual appearance of the lower frequency mechanism as temperature increases, which corresponds to the electrode impedance contribution. At $300{ }^{\circ} \mathrm{C}$, the peak in imaginary impedance arising from the bulk conductivity is apparent at around $10^{4} \omega / \omega_{0}$, as in Fig. $6 \mathrm{~b}$, but disappears from the measurable frequency range of this system at higher temperatures.

As described above, total conductivity was calculated for each composition and fitted to the Arrhenius Eq. (4). The results in Fig. 7 show trends similar to those observed by others $[27,29,31,33,36]$ who found a maximum conductivity in $20 \% \mathrm{Gd}$ doping and that at higher 


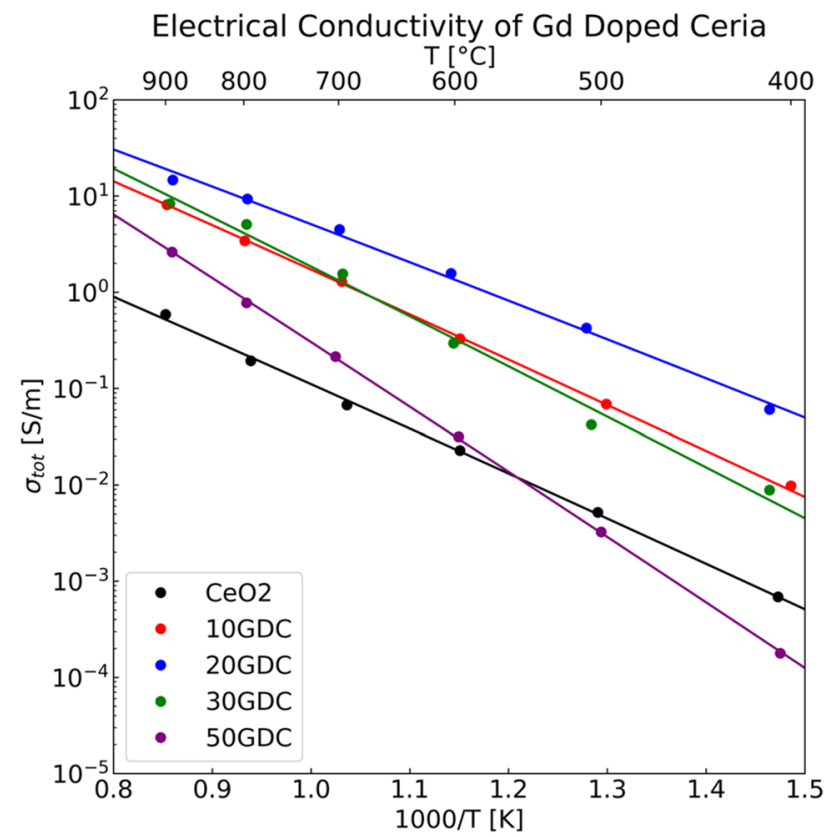

Fig. 7 Electrical conductivity measured by ac impedance spectroscopy for disk samples prepared in this work for increasing $\mathrm{Gd}$ dopant concentration over the temperature range of 300 to $900{ }^{\circ} \mathrm{C}$. Solid lines show the fit of Eq. (4) for each sample

temperatures, variation between samples decreases (Table 1). When considering our results in comparison to the literature review, we observe a larger discrepancy between the $10 \%$ than the $20 \%$, particularly at lower temperatures. We attribute this to the lower doping concentration and removal of the calcination step resulting in poor Gd diffusion. By looking at Hohnke's work, which exceeded the temperature range of others, conductivities converged with a change in activation energy at the temperature where each composition meets in the Arrhenius plot [31]. Above this temperature, samples appear to have little variation in conductivity with dopant level, suggesting doping has little effect on the overall conductivity at ultra-high temperatures. A more detailed analysis into the higher temperature conductivity is needed to confirm this hypothesis.

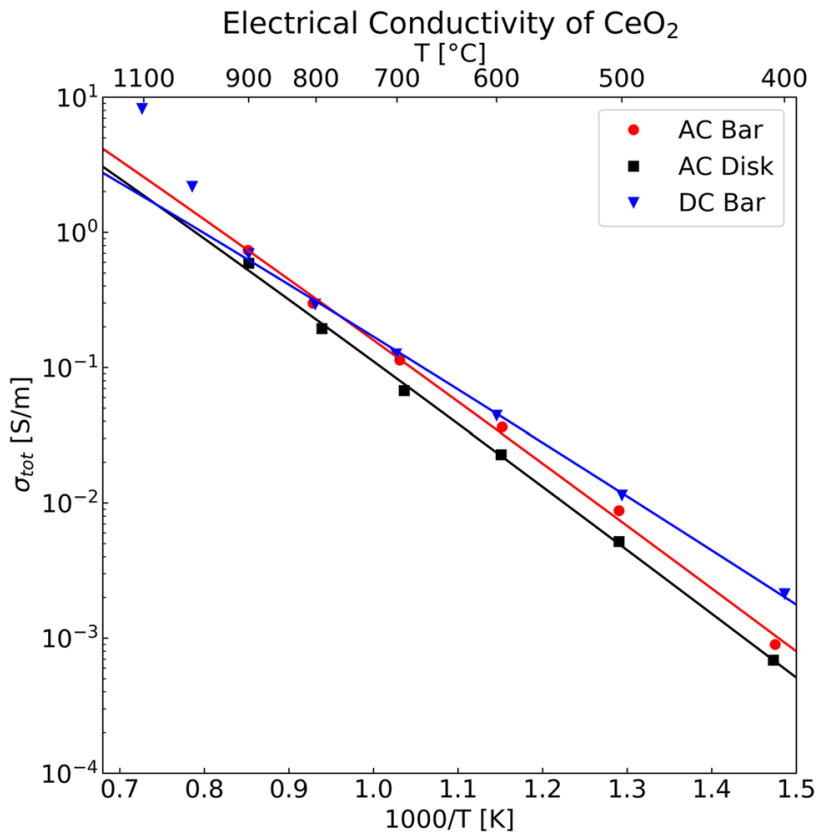

Fig. 8 Arrhenius plot of electrical conductivity of different measurement techniques for undoped ceria. Solid lines represent Arrhenius equation fitting for each method

The limiting factor for higher temperature measurements with 2-point AC EIS is the instrument resistance, which is on the order of magnitude of the samples at temperatures of $900^{\circ} \mathrm{C}$. Four-point resistance measurements are one resolution to this issue. A further study to observe discrepancies between the 2-point AC EIS and 4-point $D C$ resistance on bar geometries was done for undoped ceria. It was found that conductivities from each of the three techniques, AC EIS for disk geometries, AC EIS for bar geometries, and 4-point DC resistance for bar geometries, all range within a factor of 4 as observed in the data in Fig. 8 (Table 2). The change in mechanism at temperatures above $1000^{\circ} \mathrm{C}$ is apparent, though the number of data points is insufficient to reliably fit an activation energy. The use of bar geometries over disk geometries has little effect on the conductivity values obtained from AC impedance
Table 1 Activation energy and $A$ intercept for each of the Arrhenius equation plotted in Fig. 7 fit to Eq. (4)

\begin{tabular}{llllll}
\hline & $\mathrm{CeO}_{2}$ & $\mathrm{Gd}_{0.1} \mathrm{Ce}_{.9} \mathrm{O}_{1.95}$ & $\mathrm{Gd}_{0.2} \mathrm{Ce}_{.08} \mathrm{O}_{1.9}$ & $\mathrm{Gd}_{0.3} \mathrm{Ce}_{0.7} \mathrm{O}_{1.85}$ & $\mathrm{Gd}_{0.5} \mathrm{Ce}_{0.5} \mathrm{O}_{1.75}$ \\
\hline$E_{a}[\mathrm{eV}]$ & -1.00 & -1.01 & -0.87 & -1.11 & -1.41 \\
$\log (A)\left[\frac{\mathrm{s}}{\mathrm{m}} \mathrm{K}\right]$ & 7.1 & 8.3 & 8.1 & 8.8 & 9.6
\end{tabular}


Table 2 Fitted Arrhenius equation values of the data in Fig. 8 for the activation energy and $A$ intercept defined in Eq. (4) above

\begin{tabular}{llll}
\hline & AC disk & AC bar & DC bar \\
\hline$E_{a}[\mathrm{eV}]$ & -1.00 & -0.98 & -0.86 \\
$\log (A)\left[\frac{s}{m} K\right]$ & 7.1 & 7.2 & 6.5 \\
\hline
\end{tabular}

spectroscopy, as the activation energies are nearly equal with values of $0.98 \mathrm{eV}$ and $1.0 \mathrm{eV}$, respectively. However, there is a clear difference in activation energies between $A C$ and DC measurements performed on the bar sample. This discrepancy is possibly from error in low temperature measurements with the $\mathrm{AC}$ technique.

\section{Conclusions}

In this study, we explored the electrical properties of pure and $\mathrm{Gd}$-doped ceria to determine its viability as an electrode material for MHD power generation. While thermal engineering challenges restrict electrical measurements performed at the expected operating temperatures $\left(\sim 2000^{\circ} \mathrm{C}\right)$, it is apparent that the expected conductivity values will reach those required for efficient power generation with values on the order of $10 \mathrm{~S} / \mathrm{m}$ at temperatures as low as $1100^{\circ} \mathrm{C}$. The accumulation of data from many sources leads to a reasonable range of values which helps understand both the material property and the limits in manufacturing of GDC for MHD applications. Beyond the electrical properties, there are other important material characteristics needed to fully evaluate the suitability of GDC for MHD applications. Based on our findings, Gddoped ceria has adequate electrical properties for use in hot-electrode MHD generators.

Acknowledgements The work was supported by the U.S. Department of Energy's Crosscutting Research Program. This project was also supported by an appointment to the Science Education Programs at the National Energy Technology Laboratory (NETL), administered by ORAU through the U.S. Department of Energy Oak Ridge Institute for Science and Education.

Funding This report was prepared as an account of work sponsored by an agency of the United States Government. Neither the United States Government nor any agency thereof, nor any of their employees, makes any warranty, express or implied, or assumes any legal liability or responsibility for the accuracy, completeness, or usefulness of any information, apparatus, product, or process disclosed, or represents that its use would not infringe privately owned rights. Reference therein to any specific commercial product, process, or service by trade name, trademark, manufacturer, or otherwise does not necessarily constitute or imply its endorsement, recommendation, or favoring by the United States Government or any agency thereof. The views and opinions of authors expressed therein do not necessarily state or reflect those of the United States Government or any agency thereof.

\section{Compliance with ethical standards}

Conflict of interest On behalf of all authors, the corresponding author states that there is no conflict of interest.

\section{References}

1. Kessler R (2000) Magnetohydrodynamics. In Kirk-Othmer Encyclopedia of Chemical Technology (ed). John Wiley and Sons, INC

2. Rosa RJ (1987) Magnetohydrodynamic energy conversion. Hemisphere Pub. Corp, New York

3. Woodside CR (2014) Retrospective and prospective aspects of MHD power generation. Magnetohydrodynamic Power Generation Workshop

4. Bedick CR, Kolczynski L, Woodside CR (2017) Combustion plasma electrical conductivity model development for oxyfuel MHD applications. Combust Flame 181:225-238

5. Kayukawa N (2004) Open-cycle magnetohydrodynamic electrical power generation: a review and future perspectives. Prog Energy Combust Sci 30:33-60

6. Rudins $\mathrm{G}$ et al (1975) Joint U.S.-U.S.S.R. Test of U.S. MHD electrode systems in U.S.S.R. U-02 MHD facility (Phase I). National Technical Reports Library

7. Rudins G (1974) US and USSR MHD electrode materials development. RAND Corporation, Santa Monica, CA

8. Rudins $\mathrm{G}$ et al (1977) Joint U.S.-U.S.S.R. electrode material test system U-02 Westinghouse (Phase II). National Technical Reports Library

9. Bates JL et al (1979) Joint U.S.-U.S.S.R. Test of U.S. MHD electrode system in the U02 facility (Phase III). National Technical Reports Library

10. Telegin GP et al (1978) Tests and studies of U.S.S.R. materials at the U.S. Coal burning MHD facility UTSI-2. 40

11. Bates JL, Marchant DD (1986) Development of materials for open-cycle magnetohydrodynamics: ceramic electrode. National Technical Reports Library

12. Meadowcroft DB (1968) Electronically-conducting, refractory ceramic electrodes for open cycle MHD power generation. Energy Convers 8:185-190

13. Sadler JW et al (1977) Development, testing and evaluation of MHD materials and component designs. National Technical Reports Library

14. Scheindlin AE (1974) U25 MHD Pilot plant - Part II - MHD generator studies. USSR Institute of High Temperatures (translated)

15. Patil DS, Venkatramani N, Rohatgi VK (1988) Electrical conductivity of (ZrO2)_0.85 (CeO2)_0.12 (Y2O3)_0.03. J Mater Sci 23:3367-3374

16. Zavodinsky VG (2004) The mechanism of ionic conductivity in stabilized cubic zirconia. Phys Solid State 46:453-457

17. Ai C, Zhang Y, Wang P, Wang W (2019) Catalytic combustion of diesel soot on $\mathrm{Ce} / \mathrm{Zr}$ series catalysts prepared by sol-gel method. Catalysts 9:646

18. Badwal SPS et al (2013) Structural and microstructural stability of ceria - gadolinia electrolyte exposed to reducing environments of high temperature fuel cells. J Mater Chem A 1:10768 
19. Eguchi K, Setoguchi T, Inoue T, Arai H (1992) Electrical properties of ceria-based oxides and their application to solid oxide fuel cells. Solid State lonics 52:165-172

20. Taroca HA, Santos JAF, Dominguez RZ, Matencio T (2011) Ceramic materials for solid oxide fuel cells. In: Sikalidis $C$ (ed) Advances in ceramics-synthesis and characterization, processing and specific applications, InTech. https://doi. org/10.5772/18297

21. Tuller HL, Nowick AS (1975) Doped ceria as a solid oxide electrolyte. J Electrochem Soc 122:5

22. Mogensen M, Sammes NM, Tompsett GA (2000) Physical, chemical and electrochemical properties of pure and doped ceria. Solid State Ionics 129:63-94

23. Žguns PA, Ruban AV, Skorodumova NV (2018) Phase diagram and oxygen-vacancy ordering in the $\mathrm{CeO}_{2}-\mathrm{Gd}_{2} \mathrm{O}_{3}$ system: a theoretical study. Phys Chem Chem Phys 20:11805-11818

24. Blumenthal RN, Lee PW, Panlener RJ (1971) Studies of the defect structure of nonstoichiometric cerium dioxide. J Electrochem Soc 118:7

25. Panlener RJ (1975) A thermodynamic study of nonstoichiometric cerium dioxide. J Phys Chem Solids 36:1213-1222

26. Smyth DM (2000) The defect chemistry of metal oxides. Oxford University Press, Oxford

27. Acharya AS, Gaikwad VM, Sathe V, Kulkarni SK (2014) Influence of gadolinium doping on the structure and defects of ceria under fuel cell operating temperature. Appl Phys Lett 104:113508

28. Balazs $G$ (1995) ac impedance studies of rare earth oxide doped ceria. Solid State Ionics 76:155-162

29. Esposito V, Traversa E (2008) Design of electroceramics for solid oxides fuel cell applications: playing with ceria. J Am Ceram Soc 91:1037-1051

30. Grilo JPF, Macedo DA, Nascimento RM, Marques FMB (2019) Electronic conductivity in Gd-doped ceria with salt additions. Electrochim Acta 318:977-988

31. Hohnke DK (1981) lonic conduction in doped oxides with the fluorite structure. Solid State lonics 5:531-534

32. Kabir A et al (2019) Effect of oxygen defects blocking barriers on gadolinium doped ceria (GDC) electro-chemo-mechanical properties. Acta Mater 174:53-60

33. Kharton VV et al (2001) Ceria-based materials for solid oxide fuel cells. J Mat Sci 36:1105-1117

34. Kudo T, Obayashi H (1976) Mixed electrical conduction in the fluorite-type Cel_Gd O.J Jlectrochem Soc 123:5
35. Sındıraç C, Büyükaksoy A, Akkurt S (2019) Electrical properties of gadolinia doped ceria electrolytes fabricated by infiltration aided sintering. Solid State lonics 340:115020

36. Tianshu Z, Hing P, Huang H, Kilner J (2002) lonic conductivity in the $\mathrm{CeO} 2-\mathrm{Gd} 2 \mathrm{O} 3$ system $(0.05 \mathrm{VGd} / \mathrm{CeV} 0.4)$ prepared by oxalate coprecipitation. Solid State lonics 7

37. Wang S, Kobayashi T, Dokiya M, Hashimoto T (2000) Electrical and Ionic Conductivity of Gd-Doped Ceria. J Electrochem Soc 147:3606

38. Fagg DP, Kharton VV, Frade JR (2003) P-type electronic transport in Ce0.8Gd0.2O2- $\delta$ : the effect of transition metal oxide sintering aids. J Electroceramics 9:199-207

39. Inaba H, Tagawa H (1996) Ceria-based solid electrolytes. Solid State lonics 83:1-16

40. Torrens RS, Sammes NM, Tompsett GA (1998) Characterisation of (CeO2)0.8(GdO1.5)0.2 synthesised using various techniques. Solid State Ionics 111:9-15

41. Van Herle J et al (1996) Low temperature fabrication of $(\mathrm{Y}, \mathrm{Gd}$, $\mathrm{Sm}$ )-doped ceria electrolyte. Solid State lonics 86-88:1255-1258

42. Zhang C, Sunarso J, Zhu Z, Wang S, Liu S (2017) Enhanced oxygen permeability and electronic conductivity of Ce0.8Gd0.2O2- $\delta$ membrane via the addition of sintering aids. Solid State Ionics 310:121-128

43. Sinclair DC (1995) Characterization of electro-materials using ac Impedance Spectroscopy. Boletín de la Sociedad Española de Cerámica y Vidrio 35:55-65

44. Irvine JTS, Sinclair DC, West AR (1990) Electroceramics: characterization by Impedance Spectroscopy. Adv Mater 2:132-138

45. Grover V, Tyagi AK (2004) Phase relations, lattice thermal expansion in $\mathrm{CeO} 2-\mathrm{Gd} 2 \mathrm{O} 3$ system, and stabilization of cubic gadolinia. Mater Res Bull 39:859-866

46. Artini C, Costa GA, Pani M, Lausi A, Plaisier J (2012) Structural characterization of the $\mathrm{CeO} 2 / \mathrm{Gd} 2 \mathrm{O} 3$ mixed system by synchrotron X-ray diffraction. J Solid State Chem 190:24-28

47. Guo X, Mi S, Waser R (2005) Nonlinear electrical properties of grain boundaries in oxygen ion conductors: acceptor-doped ceria. Electrochem Solid-State Lett 8:J1

Publisher's Note Springer Nature remains neutral with regard to jurisdictional claims in published maps and institutional affiliations. 